\title{
Comparing child-feeding practices of Dominican mothers
}

Lynn M. Babington

Fairfield University, Ibabington@fairfield.edu

Follow this and additional works at: https://digitalcommons.fairfield.edu/nursing-facultypubs

Copyright 2007 Saunders (imprint of Elsevier)

NOTICE: this is the author's version of a work that was accepted for publication in Journal of Pediatric Nursing. Changes resulting from the publishing process, such as peer review, editing, corrections, structural formatting, and other quality control mechanisms may not be reflected in this document. Changes may have been made to this work since it was submitted for publication. A definitive version was subsequently published in Journal of Pediatric Nursing, 22(5), 2007.DOI: 10.1016/j.pedn.2007.07.003

\section{Peer Reviewed}

\section{Repository Citation}

Babington, Lynn M., "Comparing child-feeding practices of Dominican mothers" (2007). Nursing and Health Studies Faculty Publications. 12.

https://digitalcommons.fairfield.edu/nursing-facultypubs/12

\section{Published Citation}

Babington, L.M. (2007). Comparing child-feeding practices of Dominican mothers. Journal of Pediatric Nursing, 22(5), 388-396.

This item has been accepted for inclusion in DigitalCommons@Fairfield by an authorized administrator of DigitalCommons@Fairfield. It is brought to you by DigitalCommons@Fairfield with permission from the rightsholder(s) and is protected by copyright and/or related rights. You are free to use this item in any way that is permitted by the copyright and related rights legislation that applies to your use. For other uses, you need to obtain permission from the rights-holder(s) directly, unless additional rights are indicated by a Creative Commons license in the record and/or on the work itself. For more information, please contact digitalcommons@fairfield.edu. 


\section{Comparing Child Feeling Practices of Dominican Mothers'}

The incidence of childhood obesity in the U.S. is rising at alarming rates and is occurring in younger age groups. This trend is also increasing among children of immigrants. One in five children in the U.S. today is from an immigrant family and is at risk for developing obesity (Hernandez, 1999). Acculturation is a difficult transition for new immigrants. Maintaining healthy eating habits is particularly challenging for families as they are introduced to new foods and dietary practices at a time when their traditional foods may be unavailable. Because mothers have a major influence on the weight of infants and young children and on the eating patterns children develop, it is imperative that we understand the feeding practices, knowledge, and nutritional beliefs of immigrant mothers to help inform the development of culturally specific interventions aimed at preventing childhood obesity.

The purpose of the study was to identify Dominican mothers' views related to the introduction of food to infants and feeding practices for young children, along with their knowledge and beliefs related to the causes and health implications of childhood obesity. Two focus groups were conducted. The first focus group was conducted in the Dominican Republic (D.R.) with mothers of young children (i.e., birth to 6 years old) who lived in a small town in the western frontier area of the D.R. (Babington, 2006). The second focus group was conducted in a community center in Boston, MA with a group of Dominican mothers who had recently immigrated to the U.S. The feeding practices, beliefs, and knowledge about nutrition for young children of these two groups were compared. Findings helped to increase understanding of the

process of acculturation and its influence on feeding practices as well as mothers' knowledge and beliefs related to childhood nutrition.

The specific aims of this study were to: 
1. Describe feeding practices for infants and young children including (a) decision-making related to choice of breast or bottle feeding and length of time, (b) introduction of food into the diet, and (c) use of dietary supplements and/or vitamins.

2. Describe Dominican mothers' knowledge and beliefs regarding healthy size and weight and ideal diet for infants and young children.

3. Describe Dominican mothers' knowledge and beliefs regarding the causes and health implications of childhood obesity including (a) their perceptions related to the causes of obesity, (b) the source of their information about eating habits and obesity in children, and (c) whether or not they are able to identify health problems caused by obesity.

\section{Background and Significance}

\section{Obesity in Immigrant Children}

Although rates of childhood obesity among the general population are alarmingly high, they are highest in ethnic minority, low income, and immigrant communities (Kumanyika \& Grier, 2006). Between 1986 and 1998, overweight increased significantly and steadily for all children, but particularly for Hispanic children. By 1998, overweight prevalence for Hispanic children was reported to be $21.8 \%$ compared to $12.3 \%$ for non-Hispanic whites and $20 \%$ for African Americans (Strauss \& Pollack, 2001). Children are becoming overweight at even younger ages. A recent study found that Hispanic children under the age of 3 were twice as likely to be overweight or obese (Kimbro, Brooks-Gunn \& McLanahan, 2007). Immigrant households have a greater number of children under age 18 than native-born households (U.S. Census, 2005). One in five children in the U.S. today is from an immigrant family (Hernandez, 1999). Clearly, the health of immigrant youth will greatly impact the health of our nation. 
The most recent U.S. Census Bureau data estimated that over 28 million foreign-born persons reside in the U.S., representing $12.4 \%$ of the total population (U.S. Census Bureau, 2005). Distribution of the U.S. foreign-born population in 2000 included $51 \%$ of who were born in Latin America and the Caribbean and West Indian Islands (U.S. Census, 2006). Between the 1990 and 2000 census, there was a $50 \%$ increase in the number of individuals born in the DR (from 347,858 to 687,675 ). Given the remarkable growth in the U.S. immigrant population, the health status of racial and ethnic minorities has become an increasingly important public health issue.

Immigrants bring a rich cultural heritage with dramatically different beliefs, values, and customs. However, immigration to a new country can represent a substantial shift in a person's lifestyle, and these changes can result in increasing risk for chronic diseases, such as obesity (Satia-About, 2002). Adopting a typical American diet that is high in fat, sugar, and salt and low in fruits and vegetables increases the risk of developing obesity. Preliminary research has suggested that some of the potential causes of immigrant obesity include the effects of acculturation and mothers' misperceptions regarding the health of their children. For many immigrants, heavier children are considered healthier (Flores \& Brotanek, 2005). The Nature and Scope of Childhood Obesity

Over the past three decades, the number of children considered overweight or obese has doubled, from $15 \%$ in the 1970 s to $30 \%$ today (Paxson, Donahue, Orleans, \& Grisso, 2006). Childhood obesity has captured public attention and become a major topic on news broadcasts and talk shows. The Institute of Medicine (2005), in a report, Preventing Childhood Obesity: Health in the Balance, used the terms "epidemic," dangerous," and alarming" to describe the current situation and called for the prevention of childhood obesity to be a national priority 
(Daniels et al., 2005; Ebbeling, Pawlak, \& Ludwig, 2002; Paxson et al., 2006). Based on data from the 1999-2002 National Health and Nutrition Examination Survey, one in five children ages 2-5 and one in three children ages 6-11 met criteria for being overweight or at risk for being overweight (defined as body mass index greater than or equal to 85\%). Childhood obesity has physical and psychological health implications (Daniels, 2006; Daniels et al., 2005). The immediate and long-term physical ramifications of obesity in children and adolescents include cardiovascular problems such as hypertension, high triglycerides, hyperlipidemia, and high cholesterol (Goran, Ball, \& Cruz, 2003; Keiss et al., 2004); non-insulin dependent diabetes (Gielen \& Hambrecht, 2004; Goran et al., 2003;); increased growth in puberty followed by stunting; early onset of puberty in females and early menarche; asthma (Baruffi, Hardy, Waslien, Uyehara, \& Krupitsky, 2004; Myers \& Vargus, 2000); pancreatitis; gall bladder disease; and polycystic ovary syndrome (Myers \& Vargus, 2000). Psychological implications range from low self-esteem and depression resulting in behavior problems at school and at home (Davidson \& Birch 2001; French, Story, \& Perry 1995; Strauss, 2000) to being victims or perpetrators of bullying behaviors (Janssen, Crawford, \& Boyce, 2004).

Childhood obesity and diabetes are increasingly being observed in younger age groups (Baruffi et al., 2004). This trend is threatening the public health of our nation because childhood obesity is strongly correlated with obesity in adulthood, and adult obesity is a significant morbidity factor. Perhaps even more troubling is the Center for Disease Control and Prevention's (CDC) (1998) Pediatric Nutrition Surveillance System Annual Report, which documented that obesity during infancy persists throughout preschool years (CDC, 1998).

The increase in childhood obesity is also an economic issue. While cost estimates of treating obese children remain relatively small, they are rapidly rising. The Brookings Institution 
estimated that the costs of treating adult obesity-related health problems may now exceed the costs of treating health problems related to smoking (Sturm, 2002). Preventing the development of childhood obesity may be the key to stemming the obesity epidemic in this country.

\section{The Role of Parents}

Parents play a critical role in preventing childhood obesity and are the exclusive agents of change in the treatment of childhood obesity (Golan \& Crow, 2004; Golan, Wizman, Apter, \& Fainaro, 1998; Lindsay, Sussner, Kim, \& Gortmaker, 2006; National Association of Pediatric Nurse Practitioners, 2006; Ritchies, Welk, Styne, Gerstein, \& Crowford, 2005). Not only do parents control the food young children eat, they (also) help children develop and maintain healthful eating habits. Parents directly determine children's physical and social environments and indirectly influence behaviors, habits, and attitudes about food (Ritchies et al., 2005). During the first years of life, children learn an enormous amount about food and eating in the family context and are shaped by parents' own food preferences and selections, which in a large part are influenced by the larger cultural context (Davidson \& Birch, 2001).

In order to slow the spread of the obesity epidemic, it is critical to develop early interventions with parents to prevent obesity from developing. Understanding health practices of different cultural groups will inform the development of culturally appropriate prevention, education, and early interventions that will ultimately improve the health status of vulnerable populations. Early interventions are particularly appropriate with new immigrants as they experience acculturation into American society. 
Methods

Design

Focus group methodology was employed in this exploratory, descriptive study. Focus groups are a qualitative research tool capitalizing on group processes and interpersonal interaction to gain rich data. Focus groups serve as a useful starting point for exploratory research because they provide a means for determining how participants think and the ways in which they communicate (Bloor, Frankland, Thomas, \& Rosen, 2001, Chang \& Hsu, 2006, McLafferty, 2004).

Focus groups were used in this study with two groups of mothers to collect data about their feeding practices for infants and young children along with their knowledge and beliefs related to healthy weight and size for children and the health implications of obesity. This focus group study was the first phase of a larger research project aimed at preventing childhood obesity in immigrant children. Findings from this study informed the development of a culturally appropriate behavioral and educational intervention for the prevention of childhood obesity that is currently being tested with immigrant mothers. The use of focus groups in the context of intervention development is supported by Kidd \& Parshall (2000).

Principles of participatory action research (PAR) guided this focus group study as well as the larger research project. PAR is defined by Baum and colleagues as collective, self reflective inquiry that researchers and participants undertake to understand and improve on situations in which they find themselves with the goal of leading people to have increased control over their lives (Baum, MacDougall, \& Smith, 2006.) The principles of PAR were employed in the formulation of the focus group questions, recruitment of study participants, analysis of the data, and ultimately in the development of the intervention. The Spanish-speaking focus group 
facilitators were recent immigrants from the DR and part of the local Dominican community in Boston and advised the principal investigator (PI) in the planning and data collection phases. They were involved in the development of the focus group questions and assisted in recruiting focus group participants. Institutional Review Board (IRB) approval for the study was obtained through Northeastern University in Boston, MA.

\section{Sample and Settings}

The setting for data collection in the D.R. was a small city (i.e., population of 40,000) in the western frontier area of the country, Las Matas de Farfan. The study took place during one of the annual trips (May 2005) in which the author participates as a volunteer sponsored by Intercultural Nursing, Inc. (i.e., a volunteer nursing organization that delivers sustainable health care in impoverished rural areas of the D.R.). While participating in these annual trips to the same area in the D.R. over the last nine years, the author has gained insight and understanding of the Dominican culture (Babington, Kelley, Patsdaughter, Soderberg, \& Kelley, 1999). Data collection in the U.S. took place in a meeting room located in a community health center in a neighborhood with a large Dominican population.

Demographic characteristics of participants were very similar in both groups (see Table 1). The D.R. group consisted of 10 women, and the U.S. group included 9 women. The mean age of the U.S. group was slightly younger. Both groups had at total of 25 children, with one pregnancy in the U.S. group and two in the D.R. group. More women in the D.R. reported being married, although very few people in the D.R. are legally married; living together and making a verbal commitment is considered marriage. Therefore, when the couple splits up, it is considered a separation rather than a divorce. The annual income in the U.S. group was much higher than in the D.R. group which had annual family income of less than $\$ 868$ U.S.. However, an annual 
income of $<\$ 10,000$ is considered poverty status in the U.S., and 7 of the 10 mothers reported an income in this range.

\section{Insert Table 1}

\section{Procedure}

In the D.R., participants were recruited by word of mouth during mobile health clinics conducted in May 2005 in Las Matas de Farfan. Participants for the U.S. focus group were recruited from the Codman Square neighborhood in Boston. Participants received an unsigned informed consent letter (which was approved by Northeastern University's IRB) and completed a demographic questionnaire; both the consent letter and questionnaire were available in both Spanish and English.

Participants were asked to participate in a 45-minute focus group session moderated by the researcher through a Spanish-speaking focus group facilitator. Once it was established in the U.S. group that all participants understood English, the actual conversation flowed back and forth between Spanish and English. In the D.R., the entire session was conducted in Spanish by a Spanish speaking focus group facilitator. The sessions were audio tape-recorded. The following questions were posed to the groups to stimulate discussion.

1. How do you decide whether to breast feed or bottle feed?

2. Where do you learn (i.e., who teaches you) about breast feeding?

3. How long do you breast feed (or bottle feed) (months/years)?

4. Do you supplement breast feeding with bottles?

5. Do you give infants vitamins?

6. At what age do you first introduce semi-solid or solid foods?

7. Which foods do you introduce first? 
8. What do you think is the ideal diet for a child ages between the ages of 1 and 6 ?

9. What do you think causes children to become overweight or obese?

10. Do you think it is OK for children to be overweight?

11. What are some of the health problems that being overweight/obese can cause for children?

When each session was complete, participants in the D.R. received a gift basket, and participants in the U.S. received a gift certificate to a local Caribbean grocery store.

\section{Data Analysis}

The PI and graduate assistant conducted analysis. Audiotapes of the focus group sessions were transcribed verbatim and translated by the graduate assistant/translator. The Spanish speaking focus group facilitators and the researcher reviewed the transcriptions for completeness and accuracy. Data from the focus groups were generated from both audiotapes and field notes. Transcribed data were systematically analyzed, organized, and coded according to the specific aims of the study using a modified constant comparative method of analysis (Denzin \& Lincoln, 2000; Lincoln \& Guba, 1985). Analysis was facilitated by color-coding the transcripts by focus group session for ease in sorting the data into themes. Following immersion in the data, analysis focused on identification of emergent themes in accordance with the principles derived by Kidd and Parshall (2000).

A number of measures were employed to enhance the validity of this research. Audio taping the focus group discussion ensured the collection of accurate and detailed data. Data were independently coded by the PI and graduate assistant as a method to establish content validity (Lynn, 1986). Interrater reliability was used to confirm all themes, and an audit trail was documented throughout the process of analysis. Field notes were reviewed with the transcripts 
during the process. Finally the themes were validated and confirmed with the Spanish-speaking focus group facilitators. The data were continually analyzed to enhance the accuracy of identified themes and reported using selected quotes from participants.

Results

\section{Feeding Practices for Infants and Young Children}

Participants in both groups reported that breast feeding is more beneficial for infants than bottle feeding, and they all breast fed their infants. However, mothers in the D.R. breast fed for a longer period of time (D.R.: average $=1$ year; U.S.: average $=4-5$ months). There was also similarity in how participants in each group learned how to breast feed: mothers reported learning from their mothers, sister, and aunts. Participants in the D.R. group, however, also reported that they all attended breast feeding clinics in the public hospital in Las Matas de Farfan. One participant elaborated, "In order to register your child's birth, you have to have the form signed by the breast feeding clinic."

A theme that emerged in the U.S. group discussion on when mothers decide to discontinue breast feeding can best be described as "getting on with our lives". Participants addressed how breast feeding limits freedom for mothers by restricting their ability to be flexible with their daily schedule. There was also some discussion in the D.R. group about negative aspects of breast feeding. For example, one participant commented, "After having a couple of kids and breast feeding for so many years, your breasts start to sag and it's bad for them."

Participants in the D.R. group reported that formula was rarely used because it is expensive and rarely available in the small towns and campos. They also reported that formula was fed to infants more often in the capital city (i.e., Santo Domingo). One participant 
explained, "In the capital, if you have your baby in the hospital, you get lots of formula and diapers to take home."

Participants in both groups reported that they gave their infants vitamins. However, mothers in the D.R. reported that once their "free" three months supply was gone, they rarely purchased vitamins. Participants in the U.S. sample reported giving liquid vitamins to their infants until one year of age. These vitamins were generally obtained from the local Women, Infants, and Children (WIC) program. One participant shared, "They give us vitamins for our babies until they are a year old". Once children were over one year of age, some of the mothers reported that they gave their children vitamins, and others reported that they did not. There did not seem to be any pattern with respect to vitamin administration.

There were also similarities between the two group regarding the introduction of food to infants. Participants in both groups reported feeding their babies the broth from cooked beans and "smashed rice with a bit of bean juice". Participants in the DR group reported offering a wider variety of fruit (e.g., bananas, mangos, watermelon) than participants in the U.S. group who reported that they primary fed their infants bananas. Participants in both groups indicated that they feed their babies cow's milk after they were 12 months old. However, mothers in the D.R. groups also reported that they used goat's milk. Additionally, participants emphasized that children in the D.R. are not fed "fat or greasy foods, including meat" since they are believed to be unhealthy. Another difference in the feeding practices was that participants in the D.R. group shared that they fed their infants teas made with green leaves to "help their stomachs", while participants in the U.S. group reported some use of Redialyte ${ }^{\circledR}$ and Ensure ${ }^{\circledR}$ (both products produced and distributed by Abbott Laboratories) as nutritional supplements. Cake was reported by participants in both groups as the preferred "sweet" once children were over two years of age. 


\section{Dominican Mothers' Knowledge Regarding Healthy Size and Weight and Ideal Diet for Young}

\section{$\underline{\text { Children }}$}

Participants in both groups agreed it is unhealthy for a child to be "fat", although no participant in either group reported weighing their children. All participants in both group also agreed that exercise is healthy for all children.

With respect to the ideal diet for children under the age of 6 , several themes emerged from the discussion in the U.S. sample. Breakfast is considered to be an important meal, and most of the participants reported that they fed their children hot oatmeal or cold cereal for breakfast. One mother reported that she made eggs in the morning. Participants agreed that a piece of fruit, small sandwich (ham and cheese being the preferred), and a glass of milk was a healthy lunch, although three of the mothers shared their frustration with their children "bugging them” for pizza or McDonald's®. One mother elaborated, “They get this from their older brothers and sisters and from TV. All the kids want food that is not good for them." There was unanimous agreement that soda and chips are not good for children, but most of the participants reported that they drank soda regularly, so often their children would share their soda. Cookies were the most frequent snack, although as one mother said, "not too many cookies . . sugar is not good for kids". A typical dinner that was considered to be healthy by the group consisted of rice and beans with stewed meat (usually chicken or pork, but occasionally beef) and stewed vegetables. Even though there was discussion about the nutritional benefits of eating salads, participants reported that they rarely fed their children salad. Ice cream was considered by all to be a healthy dessert for children as long as the portions were appropriate. One participant commented, "Every kid I know, no matter how old, loves ice cream. Since it is a dairy product, I think it is healthy for children to eat ice cream as long as you don't give them too much". 
Participants in the U.S. group also discussed how they feed their children differently than if they lived in the D.R. All of the participants reported visiting the D.R. within the last 18 months. The following verbatim quote sums up the conversation in the U.S. sample about a typical diet in the D.R. and some of the differences between how children are typically fed. In the D.R., nobody has any money, so most families eat maybe bread and hot cereal for breakfast, rice and beans and vegetables at midday, and fruit and bread in the evening. Kids don't drink too much milk because it is expensive. Eggs are also a special treat because we buy them one at a time, and they are more expensive that way. It's much healthier because they don't have McDonald's and other junk food in the campos or small towns where we come from. Kids don't eat snacks except cake for birthdays and ice cream during festivals. There are some children who don't get enough good food to eat or milk to drink, so they are sick much more often than our children. There was also a discussion about the differences in activity levels between children in the D.R. and the U.S. One participant explained:

In the D.R., before kids are in school, they run around all day long. The older ones look after the little ones. They are outside all day playing. It is much healthier. We can't let our little ones outside alone here. It's dangerous, and no one looks out after them. Kids in the U.S. spend too much time inside the house watching TV.

Some of these views were supported by participants in the D.R. group, although in general, the mothers in the D.R. group thought that their children were healthier than children in the U.S.. One participant noted, "Dominicans are healthier because of the food they cook. It tastes better, is juicer, and we eat less food. Americans eat too much food." Another participant 
added, "Also, we walk everywhere. Our kids run around all day long, and American kids watch too much TV." None of the participants in the D. R. group had ever been to the U.S.; however, all 10 women indicated that they had relatives, neighbors, or friends who had lived in the U.S. for some period of time. In addition to learning about the American diet from friends and relatives, participated reported that they see many advertisements on television for different kinds of food that are not available in the D.R. One participant said, "We don't have some of the snacky food that we see on TV. We also don't have McDonald's and hamburger places. These are bad places to eat!"

The discussion continued about how difficult it is for Dominicans who move to the U.S. to continue to eat healthy foods. One participant commented, "People in the U.S. are too busy and don't cook." Another participant added, "It is so easy and cheap to buy food that isn't healthy and makes you fat."

\section{Dominican Mothers' Knowledge Regarding the Causes and Health Implications of Childhood}

\section{Obesity}

Participants in both groups linked overeating and inactivity as the major causes of obesity in children. Participants in the U.S. group discussed the practice of rewarding "good behavior" with food such as soda and cookies. One participant noted, "This leads to fat kids. Fat kids eat too much junk food. Lots of moms just give in to the kids' constant begging for junk." Participants in the U.S. group voiced concern about the unhealthy food offered in preschools and elementary schools. One mother talked about her first grader eating "bad" muffins for breakfast and pizza and juice for lunch at school. The mothers with older children all agreed that the breakfast and lunch programs at the school were not healthy for children. When asked whether 
their children brought lunches from home, the overwhelming response was that since children get free lunch, they generally ate whatever was offered at school.

There was also general agreement among participants that children staying indoors and watching television can lead to obesity. One participant explained, "TV is bad because there are so many commercials that my kids always want to go to McDonald's or want me to buy junky cereal." There was also discussion among the group that outdoor exercise is healthy for children. One participant said, "I know lots of mothers who are too lazy to take their kids to the park, and they just sit inside or drive in their cars all of the time."

Participants in the DR sample viewed their lifestyle as generally healthier for children with less "junk food or greasy food", more exercise, and more "home cooked meals".

There were some differences in the perceived causes and health implications of childhood obesity reported by participants in the two groups. Participants in the D.R. group focused on physical problems, while participants in the U.S. group also discussed social implications. Participants in the D.R. group reported that overweight children develop asthma. One participant noted, "Fat kids have trouble running and might have a stroke when they get older." One of the participants in the U.S. group initiated a discussion on the link between childhood obesity and diabetes. A similar discussion did not occur in the D.R. group. In the U.S. group, one of the participants said, "Kids get teased a lot if they are fat, and then they feel bad." This was viewed by the group to be negatively linked to obesity.

\section{Limitations}

The convenience, non-probability sample that participated in this study was small and was not representative of the broader population of Dominican mothers in the D.R. or immigrant 
mothers in the U.S. Furthermore, social desirability bias may have been present in participants' responses in the focus group sessions. However, findings from this study increase understanding of Dominican feeding practices and mothers' knowledge and beliefs related to nutrition for children and the health effects of childhood obesity. These findings were useful in developing a culturally specific intervention for the prevention of childhood obesity.

\section{Conclusion}

While there were many similarities between the two groups of Dominican mothers in child feeding practices, mothers in the U.S. reported feeling pressure from television and food offered in schools to feed their children food that they considered unhealthy. Mothers in both groups lacked basic nutritional knowledge and accurate information on the health implications of childhood obesity.

\section{Discussion}

The findings reported in this study were used in the development a culturally specific behavioral and educational obesity prevention intervention currently being tested with two groups of immigrant mothers. Improving our understanding of Dominican child feeding practices and knowledge deficits regarding the health implications of childhood obesity informed the development of content for the intervention. Understanding how television advertising influences child feeding practices and pressures children place on their parents informed the development of the behavioral components of the intervention. Additionally, as the intervention was being developed, the participants in the Boston focus group provided input into developing the structure of the intervention that is currently being tested.

In addition to developing and testing an intervention for the prevention of childhood obesity, findings from this study will be useful to nurses who work with immigrant mothers and 
their families by informing their teaching regarding healthy feeding practices for infants and children. Intervening with prospective parents before children are born and when their children are very young will be more effective in preventing childhood obesity than treatment for obesity in later years. 


\section{References}

Babington, L. M., Kelley, B. R., Patsdaughter, C. A., Soderberg, R. M., \& Kelley, J. E. (1999). From recipes to recites: Health care in the rural Dominican Republic. Journal of Cultural Diversity, 6(1), 20-25.

Babington, L. M. (2006). Understanding beliefs, knowledge, and practices of mothers in the Dominican Republic related to feeding infants and young children. Hispanic Health Care International, 4(3), 151-156.

Baruffi, G., Hardy, C. J., Waslien, C. I., Uyehara, S. J., \& Krupitsky, D. (2004). Ethnic differences in the prevalence of overweight among young children in Hawaii. Journal of the American Dietetic Association, 104(11), 1701-1707.

Baum, F., MacDougall, C., \& Smith, D. (2006). Participatory action research. Journal of Epidemiology and Community Health, 60(10), 854-857.

Bloor, M., Frankland, J., Thomas, M., \& Roson, K. (2001). Focus groups in social research. Thousand Oaks, CA: Sage.

Centers for Disease Control and Prevention. (1998). Pediatric Nutrition Surveillance System Annual Report. Atlanta, GA: Author.

Chang, M., \& Hsu, L. (2006). Qualitative research: An introduction to focus group methodology and its application. Journal of Nursing, 53(2), 67-72.

Daniels, S. R. (2006). The consequences of childhood overweight and obesity. The Future of Our Children, 16(1), 47-67.

Daniels, S. R., Arnett, D. K., Eckel, R. H., Gidding, S. S., Haymen, L. L., Kumanyika, S., et al. (2005). Overweight in children and adolescents: Pathophysiology, consequences, prevention, and treatment. Circulation, 111, 1999-2012. 
Davidson, L., \& Birch, L. (2001). Weight status, parent reaction, and self-concept in five-year old girls. Pediatrics, 107(1), 46-53.

Denzin, N. K., \& Lincoln, Y. (2000). Handbook of qualitative research. Thousand Oaks, CA: Sage.

Ebbeling, C. B., Pawlak, D. B., \& Ludwig, D. S. (2002). Childhood obesity: Public health crisis, common sense cure. Lancet, 360, 473-482.

Flores, G., \& Brotanek, J. (2005). The healthy immigrant effect: A greater understanding might help us improve the health of all children. Archives of Pediatric Adolescent Medicine, 159(3), 295-297.

French, S. A., Story, M., \& Perry, C. L. (1995). Self-esteem and obesity in children and adolescents: A literature review. Obesity Research, 3, 479-489.

Gielen, S., \& Hambrecht, R. (2004). The childhood obesity epidemic. Circulation, 109(16), 1911-1913.

Golan, M., \& Crow, C. (2004). Parents are key players in the prevention and treatment of weight-related problems. Nutrition Reviews, 62, 39-50.

Golan, M., Weizman, A., Apter, A., \& Fainara, M. (1998). Parents as the exclusive agents of change in the treatment of childhood obesity. American Journal of Clinical Nutrition, 67, 1130-1135.

Goran, M. I., Ball, G., \& Cruz, M. L. (2003). Obesity and risk of type 2 diabetes and cardiovascular disease in children and adolescents. The Journal of Clinical Endocrinology \& Metabolism, 88(4), 1417-1427.

Hernandez, D. J. (1999). Children of immigrants: Health, adjustment and 
public assistance. In D. J. Hernandez (Ed.), Children of immigrants: Health, adjustment, and public assistance (pp. 1-17). Washington, D.C.: National Academy Press.

Institute of Medicine. (2005). Preventing childhood obesity. Washington, D.C.: National Academies Press.

Janssen, I., Crawford, W. M., \& Boyce, W. F. (2004). Associations between overweight and obesity with bullying behaviors in school-aged children. Pediatrics. 113(5), 1187-1195.

Keiss, W., Bottner, A., Bluher, S., Raile, K., Galler, A., \& Kapellen, T. M. (2004). Type 2 diabetes mellitus in children and adolescents-the beginning of a renal catastrophe? Nephrology Dialysis Transplantation, 19(11), 2693-2696.

Kidd, P., S., \& Parchall, M.,B. (2000). Getting the focus and the group: Enhancing analytical rigor in focus group research. Qualitative Health Research, 10(3), 293-308.

Kimbro, R.T., Brooks-Gunn, J., \& McLanahan, S. (2007). Racial and ethnic differentials in overweight and obesity Among 3-year of children. American Journal of Public Health, 97(2), 298-305.

Kumanyika, S., \& Grier, S. (2006). Targeting interventions for ethnic minority and low- income populations. The Future of Children, 16(1), 187-20. Retrieved December 24, 2006, from http://www.futureofchildren.org/usr_doc/09_5562_kumanyika.pdf

Lincoln, Y., \& Guba, E.G. (1985). Naturalistic Inquiry. Newbury Park, CA: Sage.

Lindsay, A. C., Sussner, K. M., Kim, J., \& Gortmaker, S. (2006) The role of parents in preventing childhood obesity. The Future of Our Children, 16(1), 169-186.

Lynn, M., R. (1986). Determination and quantification of content validity. Nursing Research, 35, $382-385$. 
McLafferty, I. (2004). Focus group interviews as a data collection strategy. Journal of Advanced Nursing, 48(2), 187-194.

Myers, S., \& Vargus, Z. (2000). Parental perceptions of the preschool obese child. Pediatric Nursing, 26(1), 23-30.

National Association of Pediatric Nurse Practitioners. (2006). Identifying and preventing overweight in childhood: Clinical practice guidelines. Journal of Pediatric Health Care, 20(2) (Suppl.)

Paxson, C., Donahue, C., Orleans, T., \& Grisso, J. A. (2006). Introducing the issue: Childhood obesity. The Future of Our Children, 16(1), 3-4.

Ritchies, L.,Welk, G., Styne, D., Gersteir, D., \& Crawford, P. B. (2005). Family environment and pediatric overweight: What is a parent to do? Journal of the American Dietetic Association, 105, S70-79.

Satia-About, A,J. (2002). Dietary acculturation: Application to nutrition research and dieteticsperspective in practice. Journal of the American Dietetic Association, 102(8), 1105-1118.

Strauss, R.S. (2000). Childhood obesity and self-esteem. Pediatrics, 105(1),15-19.

Straus, R.S., \& Pollack, H.A. (2001). Epidemic increase in childhood overweight, 1986-1998. Journal of the American Medical Association, 286, 2845-2848.

Strauss, A., \& Corbin, J. (1998). Basics of qualitative research: Techniques and procedures for developing grounded theory. Thousand Oaks, CA: Sage.

Sturm, R. (2002). The effects of obesity, smoking, and drinking on medical problems and costs. Health Affairs, 21(2), 245-53.

U.S. Census Bureau. (2005). Percent of people who are foreign born: 2005 Universe: Total population. Retrieved December 24, 2006 from http://factfinder.census.gov/servlet/ 
U.S. Census Bureau. (2006). Foreign born profiles. Retrieved April 4, 2007 from http://www. census.gov/population/www/socdemo/foreign/STP-159-2000tl.html 